\title{
Preventing Contralateral Hip Fractures in the Elderly: Case Reports on Using a New Percutaneous Internal Fixation Device to Reinforce the Proximal Femur in Case of a First Low-Energy Hip Fracture
}

\section{Pieter $\mathbf{R F}^{1 *}$, Dragos $\mathrm{S}^{1}$, Tatiana $\mathrm{BH}^{2}$ and Tamas $\mathbf{I}^{1,3,4}$}

${ }^{1}$ Department of Orthopedic Surgery, University Hospitals Brussels, Campus Brugmann, Free Universities of Brussels, Brussels, Belgium

${ }^{2}$ Clinical Research Unit, University Hospitals Brussels, Campus Brugmann, Brussels, Belgium

${ }^{3}$ Department of Orthopedic Surgery and Traumatology, Odense University Hospital and Institute of Clinical Research, University of Southern Denmark, Denmark

${ }^{4}$ National Medical Academy, Paris, France

\begin{abstract}
Hip fracture in frail people is an increasing problem with a major socio-economic impact. Besides, a first hip fracture is often followed by a second fracture of the opposite hip in the following years. The authors report on four cases with extra-capsular hip fractures treated not, only for the fracture but also to avoid future contralateral fracture by implanting an innovative device as a preventive measurement.
\end{abstract}

Keywords: Proximal femur; Hip fracture; Osteoporosis; Orthopedics; Prevention; Prophylactic consolidation

\section{Introduction}

Hip fracture in frail people is an increasing problem with a major socio-economic impact. In 1950 , only $8.5 \%$ of the population was older than 65 . In 2000 , they reached $14.7 \%$ of the population, and the forecast for 2050 is $27.9 \%$ of individuals aged 65 years or more [1]. Among those living at home prior to proximal femur fracture, only $50 \%$ make it back to their pre-fractured functional status [2].

Moreover, the risk of a fracture on the contralateral side is around $9 \%$ at one year [3]. Taking in consideration the mortality associated to the second fracture (up to $64 \%$ in the following five years) and decreased quality of life [3], preventive measurements seem mandatory $[4,5]$. Fall preventive measurements are simple at low cost and go from medical check-up to rule out eye problems, dizziness and inappropriate medication to the use of sturdy shoes, lighting up the living space, removing home hazards and the use of assistive devices.

Besides, not all fractures are caused by osteoporosis so pharmacological treatments as antiresorptives - or anabolic agents can't always preclude the appearance of a contralateral hip fracture.

A new minimally invasive way to prevent this new fracture to occur is the reinforcement of the proximal femur by a reversed $\mathrm{Y}$ shaped cannulated implant (Y-STRUT ${ }^{\oplus}$, Hyprevention, Pessac, France) made out of PEEK strengthened by injected bone cement [6]. We will present four cases of patients ( 3 females, 1 male between 65 and 85 years), who are presented with an extra-capsular hip fracture where we used this device on the other hip as a preventive measure.

\section{Case Report}

\section{Case 1}

An 82 years old female living independently at her home slipped and fell in October 2014. She sustained an unstable intertrochanteric fracture type 31-A1-2 according to AO Foundation classification (see Diagnosis Proximal femur) at the left hip (Figure 1). She has a medical history of osteoporosis (T-score of -3.8 at the spine and -5.7 at the wrist) and already sustained a left wrist fracture. She also has type II Diabetes, alcoholism and tobacco abuse (one package a day), giving a non-negligible risk of subsequent fracture (calculated FRAX at $31 \%$ 10 -year probability risk of hip fracture).

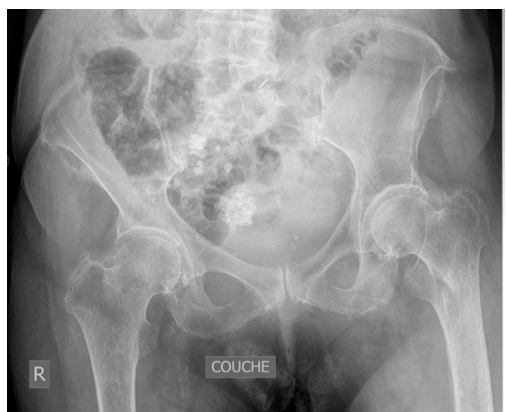

Figure 1: Radiograph of case 1: FJ showing an unstable pertrochanteric fracture type 31-A1-2 according to $\mathrm{AO}$.

After signing the informed consent, her left hip was fixed with a cephalomedullary implant (PFNA, DePuy-Synthes, Belgium). During the same operative time, the prophylactic YSTRUT ${ }^{\bullet}$ medical device (Hyprevention, Pessac, France) was placed at her right hip and bone augmentation using Cortoss ${ }^{\star}$ cement (Stryker, Belgium) was performed. Cortoss is an injectable, non-resorbable composite consisting of crosslinking resins and reinforcing glass ceramic. It filled up the guide wire trajectory close to the subchondral area of the head of femur (Figure 2). Surgical time for the placement of Y-STRUT ${ }^{\circledast}$ was 60 minutes under general anesthesia (ASA score 3).

A post-operative pain of 1 was reported at 3 weeks, on a scale from $0-10 \mathrm{~cm}$ (meaning $10 \mathrm{~cm}$ extreme pain), and 8.2 at 3 months. It should be noted that she was the only patient who complained of pain at her right hip with the $\mathrm{Y}_{-} \mathrm{STRUT}^{\oplus}$ device implanted. We report a WOMAC

*Corresponding author: Pieter RF, Department of Orthopedic Surgery, University, Hospitals Brussels, Campus Brugmann, Brussels, Belgium, Tel: +32 (0)2 4772371 E-mail: pieter.reynders@chu-brugmann.be

Received February 15, 2018; Accepted February 25, 2018; Published March 03, 2018

Citation: Pietera RF, Dragosa S, Tatianab BH, Tamasa I (2018) Preventing Contralateral Hip Fractures in the Elderly: Case Reports on Using a New Percutaneous Internal Fixation Device to Reinforce the Proximal Femur in Case of a First Low-Energy Hip Fracture. Bioceram Dev Appl 8: 110. doi: 10.4172/20905025.1000110

Copyright: ( $) 2018$ Pietera RF, et al. This is an open-access article distributed under the terms of the Creative Commons Attribution License, which permits unrestricted use, distribution, and reproduction in any medium, provided the original author and source are credited. 
Citation: Pietera RF, Dragosa S, Tatianab BH, Tamasa I (2018) Preventing Contralateral Hip Fractures in the Elderly: Case Reports on Using a New Percutaneous Internal Fixation Device to Reinforce the Proximal Femur in Case of a First Low-Energy Hip Fracture. Bioceram Dev Appl 8: 110. doi: $10.4172 / 2090-5025.1000110$

score part I (pain) of 5 at 3 months and 2 at 1 year and part II (function) of 3 at 3 months and 5 at 1 year. This groin pain did not prevent her from walking normally, in the beginning with a walking frame and thereafter without any support. The Oxford hip score has improved from 23 (low) at 3 months to 36 (average) at 1 year.

\section{Case 2}

A 65-year-old female fell in at home in May 2016. She sustained an unstable reversed oblique fracture of the right hip (Figure 3). She has a medical history of osteoporosis (T-score of -2 at the spine and -5 at the wrist), alcoholism (three units per day) and tobacco abuse (15 cigarettes per day).

After signing the informed consent, her right hip was fixed with a cephalomedullary implant (PFNA, DePuy-Synthes, Belgium). At her left hip a Y-STRUT ${ }^{ø}$ medical device (Hyprevention, Pessac, France) was placed with augmentation cement, Cortoss ${ }^{\circledR}$ (Stryker, Belgium) (Figure 4). In this case, we had some extravasation of bone augmentation laterally in the soft tissues, and an additional procedure

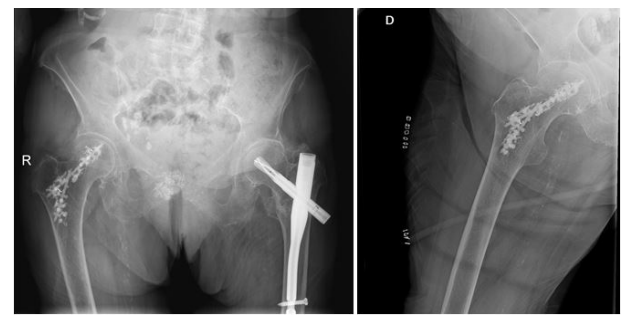

Figure 2: Radiograph of case 2: FJ, after fixing her left hip with cephalomedullary implant (PFNa, DuPuy Synthes, Belgium) on the left and the $Y$ strut on the right. Notice the distribution of the bone cement in the capitocervical portion of the proximal femur, TAD 32.

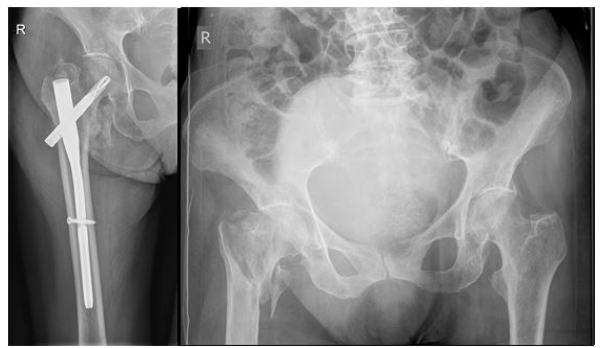

Figure 3: Radiographs of case 2: Unstable intertrochanteric fracture on the right, treated with a cephalomedullary device type PFNa.

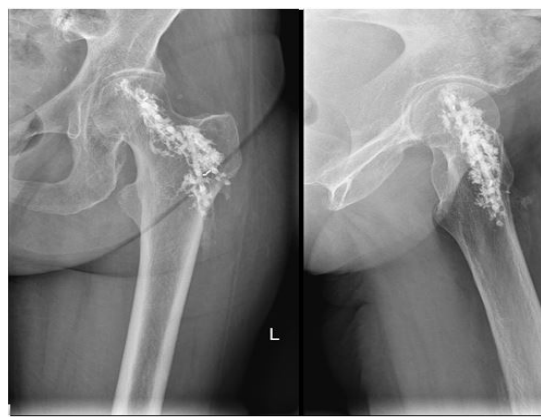

Figure 4: Radiographs after implanting Y-STRUT® on the left hip. Symmetrically placed Y-STRUT ${ }^{\circledR}$ in frontal and lateral view. Uneven distribution of bone augmentation, filling up the guide wire trajectory ending close to the subchondral plate. Spilling of bone augmentation laterally.

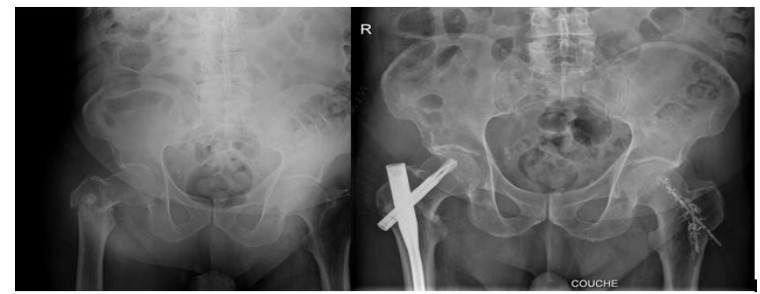

Figure 5: Radiographs of case III, stable subtrochanteric fracture on the right type 31-A3-2, treated with a cephalomedullary device type PFNa.

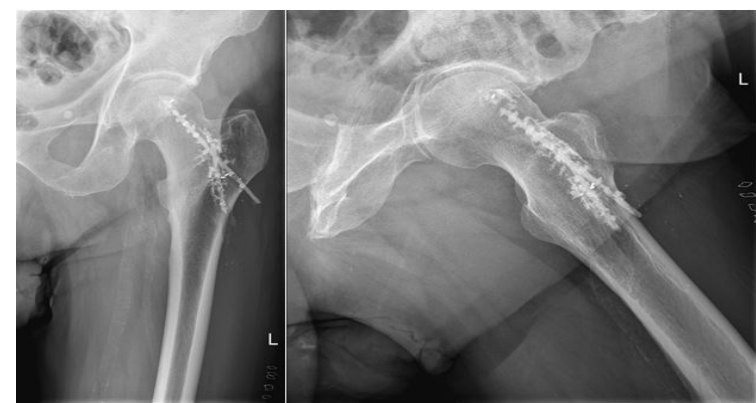

Figure 6: Radiographs of case III after implantation of the $Y$ strut. Extravasation of bone augmentation laterally. Assymetrical positioning of the $Y$ strut in the frontal view and lateral view.TAD; $42 \mathrm{~mm}$.

during surgery was necessary to remove the excess of cement. But it should also be noted that deployment of the bone augmentation was poor. Surgical time for the placement of Y-STRUT ${ }^{\oplus}$ was 100 minutes under rachi anesthesia (ASA score 2).

The patient follow-up was uneventful and she walks with a walking frame. The post-operative pain reported was 0 at 3 weeks, and 3 at 6 months. We report a WOMAC score part I (pain) of 0 at 3 and 6 months and part II (function) of 2 at 3 months and 0 at 6 months. The Oxford hip score reported was 30 (average) at 3 months and 35 (average) at 6 months. It should be noted that the patient continue to fall regularly.

\section{Case 3}

An 85 years old female living independently fell in at her home in July 2016. She sustained an unstable intertrochanteric fracture type 31A2-2 at the right hip. Among her previous medical history, we report a T-score of -1 at the spine. No alcoholism, Tobacco abuse nor previous fracture.

After signing the informed consent her right hip was fixed with a cephalomedullary implant (PFNA, DePuy-Synthes, Belgium) (Figure 5). At her left hip a Y-STRUT ${ }^{\oplus}$ medical device (Hyprevention, Pessac, France) was placed with augmentation cement Cortoss ${ }^{\star}$ (Stryker, Belgium). A cement leakage occurred cranial of the medial part of the implant 1 (most cranial one) and it also filled up the guide wire trajectory very close to the subchondral area of the head of femur (Figure 6). Surgical time for the placement of Y-STRUT ${ }^{\circledR}$ was 40 minutes under rachi anesthesia (ASA score 2).

Her follow-up was uneventful. The post-operative pain reported was 1 at 3 weeks and 2.5 at 3 months. We report a WOMAC score part I (pain) of 12 at 3 months and part II (function) of 48 at 3 months. The Oxford hip score was 16 (bad) at 3 months. She had blood transfusions of two pockets of whole blood, hematoma at the greater trochanter right and left, but no special measures were needed. 
Citation: Pietera RF, Dragosa S, Tatianab BH, Tamasa I (2018) Preventing Contralateral Hip Fractures in the Elderly: Case Reports on Using a New Percutaneous Internal Fixation Device to Reinforce the Proximal Femur in Case of a First Low-Energy Hip Fracture. Bioceram Dev Appl 8: 110. doi: $10.4172 / 2090-5025.1000110$

Page 3 of 5

\section{Case 4}

An 82 years old male fell in a nursing home in April 2017. He sustained an unstable subtrochanteric fracture type 31-A3-2 at the right hip with a fracture extension in the great trochanter. Among his previous medical history, we only report tobacco abuse (one packagea day). After signing the informed consent her right hip was fixed with a cephalomedullary implant (PFNA, DePuy-Synthes, Belgium) (Figure 7). At his left hip a Y-STRUT ${ }^{\circledast}$ medical device (Hyprevention, Pessac, France) was placed with augmentation cement, Cortoss ${ }^{\star}$ (Stryker, Belgium). In this case we had some extravasation of bone augmentation laterally in the soft tissues, of which some of the spilling needed to be removed during surgery (Figure 8). Surgical time for the placement of Y-STRUT $^{\oplus}$ was 30 minutes under rachi anesthesia (ASA score 2). His follow-up was uneventful. The post-operative pain reported was 1 at 3 weeks on a scale from $0-10 \mathrm{~cm}$. It should be noted that he had hematoma at the greater trochanter right and left: right (PFNA) grade II and left $\left(\right.$ Y-STRUT $^{\oplus}$ ) grade I, but no special surgical measure were needed.

\section{Discussion and Conclusion}

The authors share their early results in the handling of an implant to prevent a new hip fracture on the contralateral side. Our experience with this device is limited to four cases. In all four cases we could bring in successfully the reversed Y-STRUT ${ }^{\oplus}$ made of PEEK. Injection of the bone augmentation into the annulated polymer rod was straight forward in two cases. In one case there was not sufficient dispersion of the product in the head of femur. In other two cases, there was some spilling of the bone augmentation laterally out of the cortex into the soft tissue. In these two cases we removed nearly all the hardened bone augmentation polymer. We feel that attention should be made to avoid deep penetration of the guide pin into the head of femur. Accidental intra-articular perforation of the guide pin is not always visible on standard AP and lateral views during fluoroscopy. In all cases the guide pin trajectory was filled with Cortoss ${ }^{\oplus}$ bone augmentation.

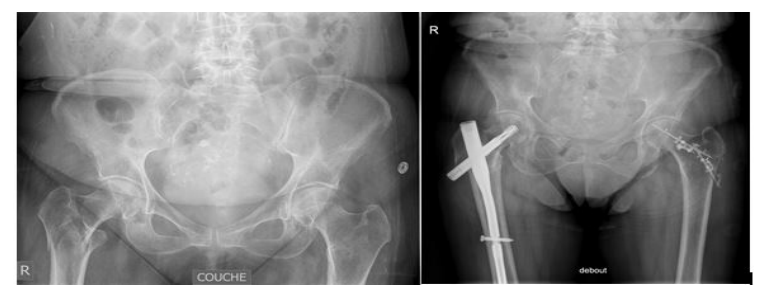

Figure 7: Radiographs of case 4 , showing an unstable reversed oblique fracture right hip. Hipfracture was fixed with a cephalomedullary implant, PFNa.



Figure 8: Radiographs after implanting the $Y$ strut left hip. Symmetrically placed $\mathrm{Y}$ strut in frontal and lateral view. Uneven distribution of bone augmentation,Cortoss ${ }^{\circledR}$ in the neck of femur. Filling up the guide wire trajectory ending close to the subchondral plate. Spilling of bone augmentation laterally. TAD; $0 \mathrm{~cm}$.
Our procedure was lengthy in time. This can be partly explained by the fact that the surgical team (surgeons and theater staff) was not fully used with this technique. When future handling skills improves so can operative time substantially be reduced. Except one, all our cases were comfortable with the reinforced non fractured hip.

We did not encounter severe complications necessitating an additional medical or surgical procedure and no fracture occurred during the follow-up of these patients. We hope to continue to offer this preventive treatment in avoiding a new hip fracture which is often devastating for these frail patients.

\section{Patient Details}

\section{Case 1: FJ}

- Age 82

- Length $152 \mathrm{~cm}$

- Weight $52 \mathrm{~kg}$, BMI 22.5

- Alcoholism

- Tabaco abuse, one package a day

- Previous medical \& surgical ailments

I. Osteoporosis, T-score -3.8 Spine, -5.7 wrists.

II. Diabetes type II

III. Hypercholesterolemia

IV. Zrterial hypertension

V. Arterial atherosclerosis

VI. Intestinal occlusion

VII. Partial gastrectomy

VIII. Abdominal aneurysm

IX. Cataract bilateral

$X$. Left wrist fracture

XI. TKA right

\section{- Surgical details}

I. Surgical time for the placement of the Y strut 60 minutes

\section{Rachi anesthesia}

III. Y strut left hip, PFNa right hip.

IV. Cortoss ${ }^{\bullet}$ filled up the guide wire trajectory close to the subchondral area of the head of femur.

\section{- Blood analysis}

I. Pre-op; Hb 14.3g/dl, RBC 4.9 million per liter mcL ( 4.2-5.4 $\mathrm{mcl}$ ),C Reactive Protein or CRP $119 \mathrm{mg} / \mathrm{L}$

II. Post-op; Hb 11,8g/dl, RBC 4.08 mcL, CRP 20 mg/L

\section{- Post-operative pain}

I. Y strut ; $8.2 \mathrm{~cm}, 5 \mathrm{~cm}$ (at one year) on a scale from $0-10 \mathrm{~cm}$. Meaning $10 \mathrm{~cm}$, extreme painful.

II. Womac score part I (pain) 5 and 2 (one year), part II (function) 3 and 5 (one year). 
Citation: Pietera RF, Dragosa S, Tatianab BH, Tamasa I (2018) Preventing Contralateral Hip Fractures in the Elderly: Case Reports on Using a New Percutaneous Internal Fixation Device to Reinforce the Proximal Femur in Case of a First Low-Energy Hip Fracture. Bioceram Dev Appl 8: 110. doi: $10.4172 / 2090-5025.1000110$

Page 4 of 5

\section{- Oxford hip score}

I. 23 (average), 40-48 (good) at one year.

\section{Case 2 VDBY}

- Age 85

- Length $168 \mathrm{~cm}$

- Weight $56 \mathrm{~kg}$

• BMI 19.9

- Alcoholism: negative

- Tabaco abuse: negative

- Previous medical and surgical ailments

I. Osteoporosis, T-score -1 Spine

II. Arterial hypertension

III. Atrial Fibrillation

\section{- Surgical details}

I. Surgical time for the placement of the Y strut 40 minutes

II. Rachi anesthesia

III. Y strut left hip, PFNa right hip.

IV. Cortoss ${ }^{\oplus}$ leakage cranial of the medial part of the implant I (most cranial one). Also filling of the guide wire trajectory very close to the subchondral area of the head of femur.

\section{- Blood analysis}

I. Pre-op; Hb 10,7 g/dl, RBC 3.6 mcL ( 4.2-5.4 mcl), CRP 51.8 mg/L

II. Post-op; Hb 8,1 g/dl, RBC 2.7 mcL, CRP 105.9 mg/L

- Post-operative pain Y strut; $0 \mathrm{~cm}, 2.5 \mathrm{~cm}$ (at four months) on a scale from $0-10 \mathrm{~cm}$

- Womac score part I (pain) 2.5 (four months), part II (function) 22 (four months)

- Oxford hip score; 16 (bad) at four months.

- Complications; Blood transfusions of two pockets of whole blood, Hematoma at the greater trochanter left and right; no special measurements were needed.

\section{Case 3 VI}

- Age 82,

- length $178 \mathrm{~cm}$,

- weight $75 \mathrm{~kg}$,

- BMI 23.7

- Alcoholism: negative

- Tabaco abuse: one package a day.

- Previous medical and surgical ailments;
I. Osteoporosis: negative
II. Macular degeneration
III. Cataract bilateral

\section{Resection of internal hemorroids}

V. Diverticulosis

\section{- Surgical details}

I. Surgical time for the placement of the Y strut 60 minutes.

II. Rachi anesthesia

III. Y strut left hip, PFNa right hip.

IV. Cortoss ${ }^{\oplus}$ spilling of Cortoss ${ }^{\oplus}$ laterally in the soft tissues. Additional procedure during surgery was necessary; removal of bone augmentation.

\section{- Blood analysis}

I. Pre-op; Hb 13,6 g/dl, RBC 4.4 mcL ( 4.2-5.4 mcl), CRP 38.7 mg/L

II. Post-op; Hb 11.3 g/dl, RBC 3.6 mcL, CRP 37 mg/L

- Post-operative pain Y strut; $0 \mathrm{~cm}, 2.5 \mathrm{~cm}$ (at four months) on a scale from $0-10 \mathrm{~cm}$.

- Womac score part I (pain) 2.5 (four months), part II (function) 22 (four months)

- Oxford hip score; 16 (bad) at four months.

- Complications; Hematoma at the greater trochanter left and right; left (Y strut) grade I, right (PFNa) grade II. No special surgical measurements were needed

\section{Case 4 VBF}

- Age 65

- length $160 \mathrm{~cm}$

- weight $68 \mathrm{~kg}$

- BMI 26.17

- Alcoholism: three units per day.

- Tabaco abuse: 15 cigarettes per day.

- Previous medical and surgical ailments;

I. Osteoporosis: T-score -2 spine, -5 wrist

II. Arterial hypertension

III. Thyroid nodules removed

IV. Low vitamine D levels.

\section{- Surgical details}

I. Surgical time for the placement of the Y strut 100 minutes.

II. Rachi anesthesia

III. Y strut left hip, PFNa right hip.

IV. Cortoss spilling of Cortoss ${ }^{\otimes}$ laterally in the soft tissues. Additional procedure during surgery was necessary; removal of bone augmentation.

\section{- Blood analysis}

I. Pre-op; Hb 12,8 g/dl, RBC 3,9 mcL ( 4.2-5.4 mcl), CRP 4 mg/L

II. Post-op; Hb 9,7 g/dl, RBC 2,9 mcL, CRP 172 mg/L

- Post-operative pain Y strut; $0 \mathrm{~cm}, 3 \mathrm{~cm}$ (at six months) on a scale from $0-10 \mathrm{~cm}$. 
Citation: Pietera RF, Dragosa S, Tatianab BH, Tamasa I (2018) Preventing Contralateral Hip Fractures in the Elderly: Case Reports on Using a New Percutaneous Internal Fixation Device to Reinforce the Proximal Femur in Case of a First Low-Energy Hip Fracture. Bioceram Dev Appl 8: 110. doi: $10.4172 / 2090-5025.1000110$

Page 5 of 5

- Womac score part I (pain) 0, part II (function) 2 at four months, part I 0 , partII 0 at six months.

- Oxford hip score; 40-48 (good) and 30-39 (average) at four months.

- Complications; Intra-operative there was some spilling of bone augmentation in the soft tissue which needed to be removed.

- Patient continue to fall regularly.

\section{Competing Interests}

All authors declare that they have no competing interests.

\section{Acknowledgements}

None.

\section{Funding}

This study was funded by Hyprevention, Pessac, France. The sponsor provided financial support for the conduct of this research but was not involved in the collection, analysis and interpretation of data.

\section{Compliance with Ethical Standards}

\section{Conflicts of interest}

None.

\section{Human and animal rights}

All procedures performed in this study involving human participants were in accordance with the ethical standards of the institutional and/or national research committee and with the 1964 Helsinki Declaration (The Code of Ethics of the World Medical Association) and its later amendments or comparable ethical standards.

\section{Informed consent}

Informed consent was obtained from all individual participants included in the study.

\section{References}

1. Court-Brown CM, Biant L, Bugler KE, McQueen MM (2014) Changing epidemiology of adult fractures in Scotland. Scott Med J 59: 30-34.

2. Koval KJ, Skovron ML, Aharonoff GB, Zuckerman JD (1998) Predictors of functional recovery after hip fracture in the elderly. Clin Orthop Relat Res 348: 22-28.

3. Ryg J, Rejnmark L, Overgaard S, Brixen K, Vestergaard P (2009) Hip fracture patients at risk of second hip fracture: a nationwide population-based cohort study of 169, 145 cases during 1977-2001. J Bone Miner Res 24:1299-1307.

4. Chiarello E, Tedesco G, Cadossi M, Capra P, Terrando S, et al. (2016) Surgical prevention of femoral neck fractures in elderly osteoporotic patients. A literature review. Clin Cases Miner Bone Metab 13: 42-45.

5. Giannini S, Luciani D, Chiarello E, Cadossi M (2011) Osteosynthetic improvement of osteoporotic bone: Prevention surgery. Clin Cases Miner Bone Metab 8: 51-54.

6. Szpalski M, Jc LH, Jayankura M, Reynders P, Maas C (2017) Contralateral prophylactic reinforcement in case of first low-energy hip fracture: First-in-man clinical data of a new percutaneous internal fixation device. J Osteopor Phys Act 5. 